\title{
Decision support system for collision avoidance at sea
}

\author{
Agnieszka Lazarowska, M.Sc \\ Gdynia Maritime University
}

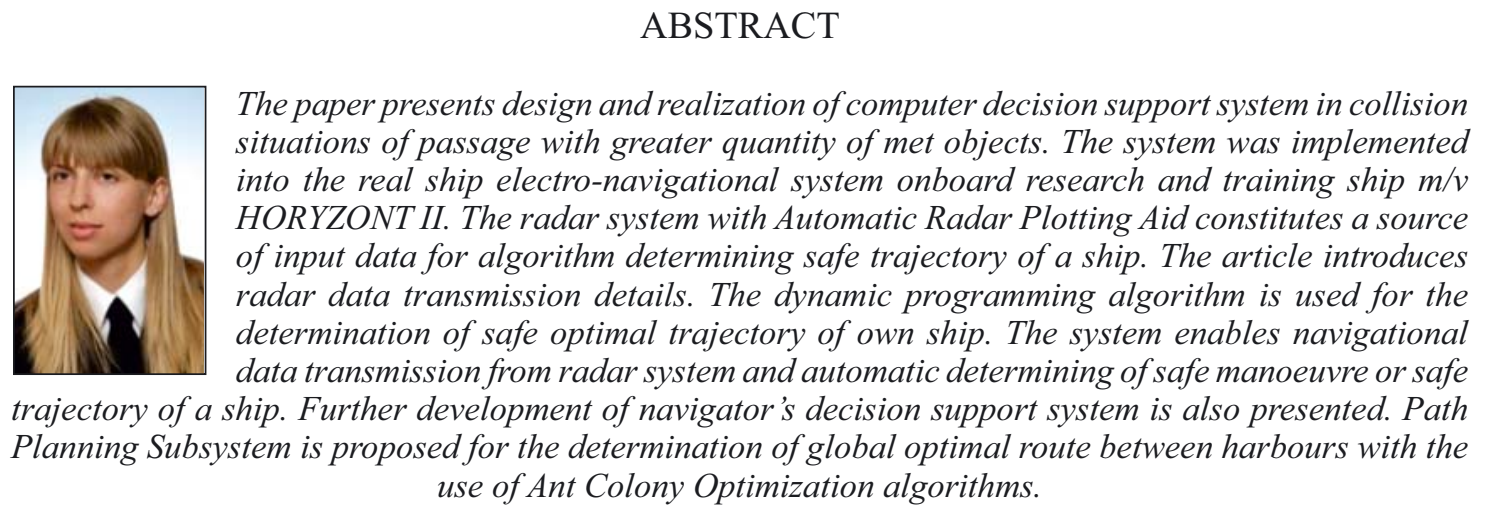

Keywords: anti-collision system; collision avoidance; safety of navigation; safe ship control; computer simulation; decision support system; navigational data; marine navigation; path planning; ant colony optimization

\section{INTRODUCTION}

Technological development led to an increased marine traffic, which caused navigation to become more demanding for deck officers. Assertion of safe navigation simultaneously with minimal operational costs constitutes the main issue in presentday marine transport. Carrying out navigation represents a complex process, because it requires continuous analyzing of huge amount of information. Incorrect assessment of current navigational situation can lead to collision situations often with very tragic consequences. Therefore it is necessary to support deck officers in anti-collision decision making process.

Currently onboard a ship the function of anti-collision system is accomplished by Automatic Radar Plotting Aid (ARPA). According to the requirements of Safety of Life at Sea Convention (SOLAS), enacted by International Maritime Organization (IMO), all ships of 10000 gross tonnage and over constructed on and after 1 July 2002 have to be equipped with Automatic Radar Plotting Aid [1]. ARPA system provides the possibility to track automatically at least 20 targets. The system also generates dangerous target alarm which indicates that the computed values of Time to the Closest Point of Approach (TCPA) and Distance of the Closest Point of Approach (DCPA) exceed the specified safe limits. ARPA system offers also a collision avoidance support function called trial manoeuvre. By using this function the deck officer has the opportunity to check the effects of own ship planned manoeuvre. It enables simulation of course change as well as speed change of own vessel [2]. Therefore there is still a possibility to improve performance of anti-collision system by implementation of a decision support system automatically determining the safe trajectory of own ship.

Human error causes $75-96 \%$ of marine accidents [3]. Application of a system eliminating human subjectivism in decision making process will cause the number of ship accidents to decrease, providing protection of human life and health, transported cargo and natural environment. Moreover the system will also assure economical transport by taking into account optimality criterion in the form of the smallest lost of way on overtaking other ships.

\section{DECISION SUPPORT SYSTEM}

The role of the decision support system is to aid the deck officer in the process of choosing the anti-collision manoeuvre. The main function of the system is to automatically determine safe manoeuvre or safe trajectory of own ship. It is achieved by application of computer algorithms. In the designed system input data for the algorithm are collected from Automatic Radar Plotting Aid.

Designed Navigator's Decision Support System (NDSS) is composed of two subsystems - Navigational Situation Display System (NSDS) and Determining Safe Trajectory System (DSTS) (Fig. 1). The first one collects input data from ARPA system and displays current navigational situation. It also contains a system log to save the data received from 
ARPA system. The second subsystem is responsible for the performance of anti-collision calculations. Initialisation of this subsystem is achieved manually by the operator or automatically, after activation of dangerous target alarm in ARPA system.

Foundations of the system include collecting of input data describing current navigational situation from Automatic Radar Plotting Aid, taking into account specific character of safe ship control process, characterized by great course changes in range from $20^{\circ}$ to $90^{\circ}$ and reduction of speed of no more than $30 \%$ and meeting requirements of International Regulations for Preventing Collisions at Sea (COLREGS). It also takes into consideration weather conditions distinguishing between situations of good and poor visibility and includes dynamic characteristics of own ship $[4,5]$.

To sum up, the system provides automatic anti-collision decision support in near real-time, reliable operation, not causing disruption in operation of basic anti-collision system, user-friendly and clear presentation of proposed manoeuvre.

Tasks realized by the system comply automatic collection of data concerning current navigational situation, analysis of current navigational situation, indicating dangerous situations and showing present level of navigational safety and automatic determination of anti-collision manoeuvre.

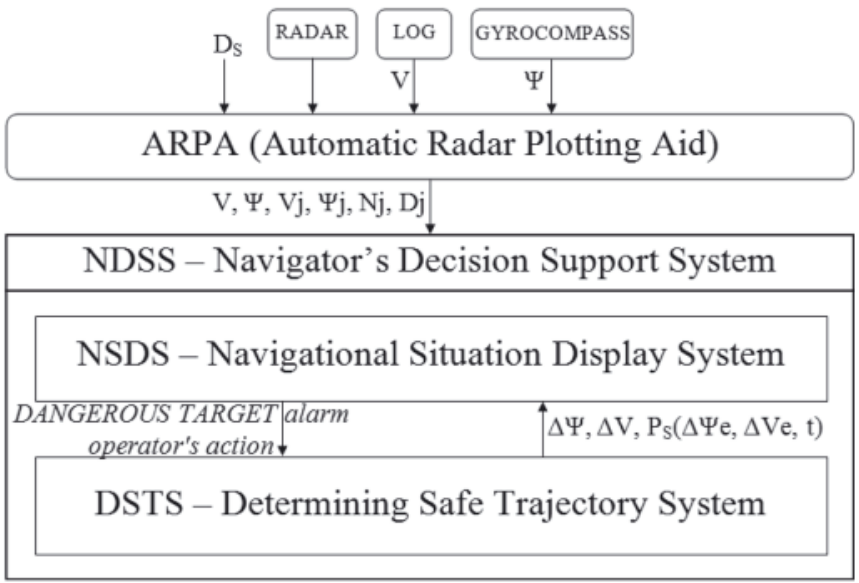

Fig. 1. Block diagram of decision support system. Ds-safe distance, $\boldsymbol{\Psi}$ - own ship course, $\boldsymbol{V}$ - own ship speed, $\boldsymbol{\Psi j}$-tracked target course, $\boldsymbol{V} \boldsymbol{j}$-tracked target speed, $\boldsymbol{N} \boldsymbol{j}$-tracked target bearing from own ship, $\boldsymbol{D} \boldsymbol{j}$-tracked target distance from own ship, $\boldsymbol{\Delta} \boldsymbol{\Psi}$-manoeuvre of course change, $\Delta V$ - manoeuvre of speed change, $\boldsymbol{P s}(\boldsymbol{\Delta} \boldsymbol{\Psi} \boldsymbol{e}, \boldsymbol{\Delta V} \boldsymbol{e}, \boldsymbol{t})$ - safe ship trajectory

\section{AUTOMATIC RADAR PLOTTING AID AS A SOURCE OF DATA FOR ANTI- COLLISION CALCULATIONS}

On the basis of signals transmitted from radar's transceiver extractor determines position of detected targets - bearing $\mathrm{N}_{j}$ and distance $D_{j}$ from own ship. In the next step, computer system calculates motion parameters - course $\Psi_{\mathrm{j}}$ and speed $\mathrm{V}_{\mathrm{j}}$ of tracked targets and approach parameters - distance of the closest point of approach DCPA and time to the closest point of approach TCPA. Despite the signals from radar system ARPA receives also data from gyrocompass and log about own ship course and speed.

To summarize, ARPA system constitutes a source of the following parameters: course and speed of own ship, target vessel course, speed, bearing and distance from own ship (Fig. 2). These parameters compose input data to navigator's decision support system. Despite these parameters, in the input to decision support system there has to be included information about safe distance Ds. This parameter is estimated by the navigator and describes minimal acceptable distance of passing met objects by own ship.

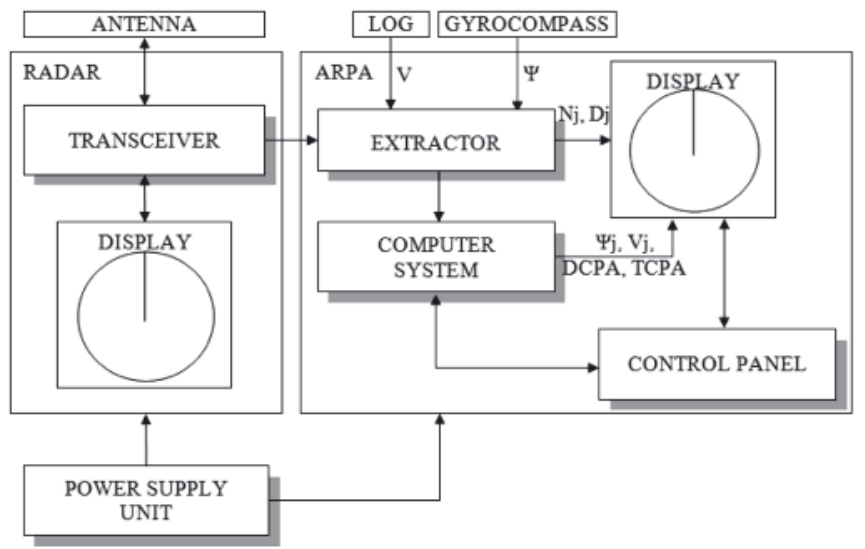

Fig. 2. Block diagram of radar and ARPA. $\boldsymbol{\Psi}$-own ship course, $\boldsymbol{V}$-own ship speed, $\boldsymbol{\Psi} \boldsymbol{j}$-tracked target course, $\boldsymbol{V} \boldsymbol{j}$-tracked target speed, $\boldsymbol{N} \boldsymbol{j}$ - tracked target bearing from own ship, $\mathbf{D} \boldsymbol{j}$-tracked target distance from own ship, DCPA - tracked target Distance of the Closest Point of Approach TCPA - tracked target Time to the Closest Point of Approach

\section{SPECIFICATION OF RADAR DATA TRANSMISSION TO DECISION SUPPORT SYSTEM}

The data transmission is performed in accordance with IEC61162-1 standard specified by International Electrotechnical Commission and is in a close convergence with NMEA 0183 standard. The IEC-61162-1 standard defines an interface requirements for data communication between maritime electronic instrument and external device. Communication is performed with the use of serial asynchronous data transmission of RS 232 type. Applied baud rate is 4800 bits per second. The data frame consists of one start bit, 8 data bits and one stop bit. There is no parity bit. The data frame structure is shown in Figure 3. Besides the definition of data frame format, IEC 61162-1 standard characterizes also the sentence structure. Figure 4 presents an example of NMEA data received from GPS eTrex Legend.

It is possible to transmit different navigational data, among others, concerning geographic position of our ship - GLL, depth below transducer - DBT, wind direction and speed - MWD or rate of turn - ROT. The selection of transmitted sentences is configurable and can be changed with the use of service menu of our ARPA system. Via the service menu we can also configure the transmission frequency of every output sentence. In SAM Electronics Radarpilot 1100 system it can be selected from 4 different values: 1, 5, 10 or 30 seconds, when the standard repetition time of OSD sentence is 1 second and of TTM sentence is 10 seconds or more.

Data needed for anti-collision calculations are included in sentences with sentence formatters marked OSD and TTM. The first one describes own ship data when the second one defines tracked target message. In the sentence before the sentence formatter appears a talker identifier that specifies the device which constitutes the source of data. When the data are received from radar system including ARPA, the talker identifier is marked with RA. In sentences defining own ship and tracked target data there can also be found characters used for marking reference system on which the calculations of vessel course and speed are based, B means bottom tracking $\log$, M stands for manually entered, W for water referenced, $\mathrm{R}$ means radar tracking and $\mathrm{P}$ positioning system ground reference. There are also symbols representing speed units, 
$\mathrm{K}$ means $\mathrm{km} / \mathrm{h}, \mathrm{N}$ stands for knots and $\mathrm{S}$ for statute miles $/ \mathrm{h}$. In addition tracked object message defines target status, which can be marked as L for target that has been lost, Q for query, which means that the target is in the process of acquisition and $\mathrm{T}$ for tracking. Moreover, tracked target message includes information presenting type of acquisition. It can be marked with a for automatic, $\mathrm{M}$ for manual or $\mathrm{R}$ for reported, for example from AIS $[6,7,8]$.

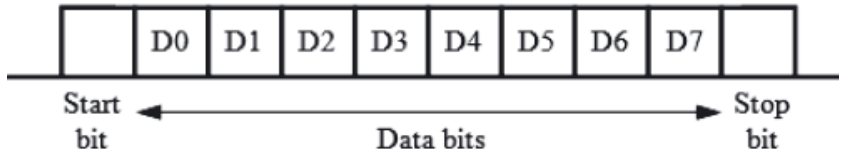

Fig. 3. Data frame structure

The sentence structures concerning own ship data and tracked target message are as follows:

\$RAOSD,a.a,A,c.c,X,x.x,Y,y.y,z.z,N*hh $<$ CR $><$ LF $>$

RA - talker identifier: RA - radar

OSD - sentence formatter: OSD - own ship data

a.a - heading, degrees true

A - heading status: a -valid, $\mathrm{V}$-invalid

c.c - vessel course, degrees true

$\mathrm{X}$ - course reference: W -water-referenced

$\mathrm{X} . \mathrm{X}$ - vessel speed

$\mathrm{Y}$ - speed reference: $\mathrm{W}$-water-referenced

y.y - vessel set, degrees true

Z.Z - vessel drift (speed)

$\mathrm{N}$ - speed units: $\mathrm{N}$ - knots

\$RATTM,aa,b.b,c.c,T,t.t,x.x,T,y.y,z.z,X,n,Y,R,hhmmss. ss, $\mathrm{M}^{*} \mathrm{hh}<\mathrm{CR}><\mathrm{LF}>$

RA - talker identifier: RA - radar

TTM - sentence formatter: TTM -tracked target message

aa - target number: 00 to 99

b.b - target distance from own ship

c.c - bearing from own ship

$\mathrm{T}$ - degrees true

t.t - target speed

$\mathrm{x} . \mathrm{X}$ - target course,

y.y - DCPA - distance of closest point of approach

Z.Z - TCPA - time to closest point of approach [min]

$\mathrm{X}$ - speed, distance units

n- user data (eg. target name)

Y - target status: L-lost, Q - query (target in the process of acquisition), $\mathrm{T}$-tracking

$\mathrm{R}$ - reference target (used to determine own ship speed)

hhmmss.ss- time of data (UTC)

$\mathrm{M}$ - type of acquisition: a -automatic, M-manual, R-reported (eg.AIS)

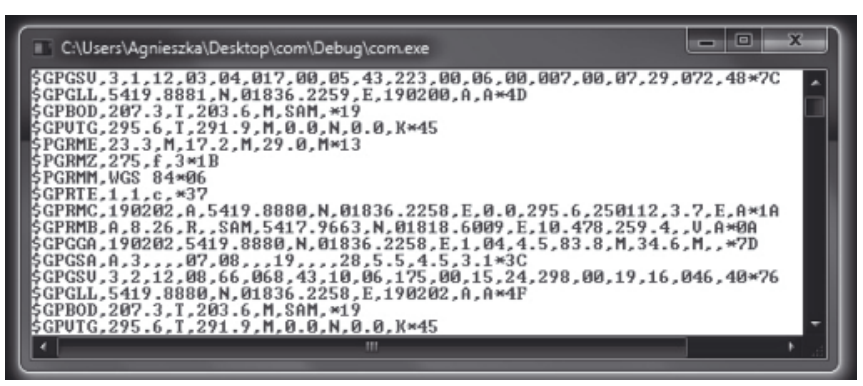

Fig. 4. NMEA data received from GPS eTrex Legend produced by Garmin with the use of application implemented in C programming language

\section{COMPUTER PROGRAMME FOR \\ COLLECTING RADAR DATA AND \\ CALCULATING SAFE TRAJECTORY OF OWN SHIP}

Various methods were proposed by many researchers for the determination of anti-collision manoeuvres, among others, game control methods $[9,10,11,12,13]$, neural networks [14], fuzzy logic $[15,16,17,18]$, evolutionary and genetic algorithms $[19,20]$ were applied.

Primary implementation of the designed system was conducted with the use of dynamic programming algorithms for determination of safe optimal trajectory of own ship implemented in Matlab environment [21,22]. Applied dynamic programming method takes into consideration dynamics of own ship and requirements of International Regulations for Preventing Collisions at Sea, what is essential in safe ship control process. The application executing transmission of anti-collision data was also designed in Matlab software and integrated with the algorithm determining the safe trajectory of own ship.

First two steps of communication algorithm are formed by the definition of serial port used for communication with ARPA system and configuration of its parameters. Transmission speed described as baud rate has to be set to 4800 bits per second. The next action to be taken is opening the connection. From that moment all available data are received via serial interface. If it is not possible to restrict transmitted sentences only to these with OSD and TTM sentence formatter, because access to service menu of radar system is unavailable, there exists a need to filter the data stream to obtain only strings marked with '\$RAOSD' and '\$RATTM'. These obtained strings have to be parsed then to select data used as an input to anti-collision calculations. So parsing routines have to be used to obtain own ship course and speed from OSD string and target vessel course, speed, bearing and distance from own ship from TTM string. After acquisition of necessary data the connection can be closed and action passed to anti-collision algorithm, as a result of which consecutive course and/or speed changes of our ship are obtained. Consecutive steps executed by communication algorithm are shown in Figure $5[23,24]$.

\section{EXPANDED DECISION SUPPORT SYSTEM}

Harris, Tran and Wilson proposed a collision avoidance system called Maritime Avoidance Navigation, Totally Integrated System (MANTIS), which is composed of the Localisation of Vessel States and it's Environment (LVSE), Automatic Collision Avoidance Advisory Service (ACAAS), an Integrated Display System (IDS), Path Planning and Scheduling Service (PPSS) and Automated Ship Guidance and Control (ASGC). Their proposal stimulated further development of decision support system presented in this paper [25].

Decision support in the ship control process should be composed of two tasks. Besides advising in anti-collision decision making process, it should also constitute a tool for determination of optimal route of passage between harbours. For that reason an extended version of decision support system is proposed. The system of hierarchical, multilayer structure includes Path Planning Subsystem (PPS) for the determination of global route from departure to destination harbour and Determining Safe Trajectory Subsystem (DSTS) for the determination of local route. DSTS system operation is initialized manually by the operator or automatically, when dangerous target alarm is activated in ARPA system. It calculates anti-collision trajectory from current position 


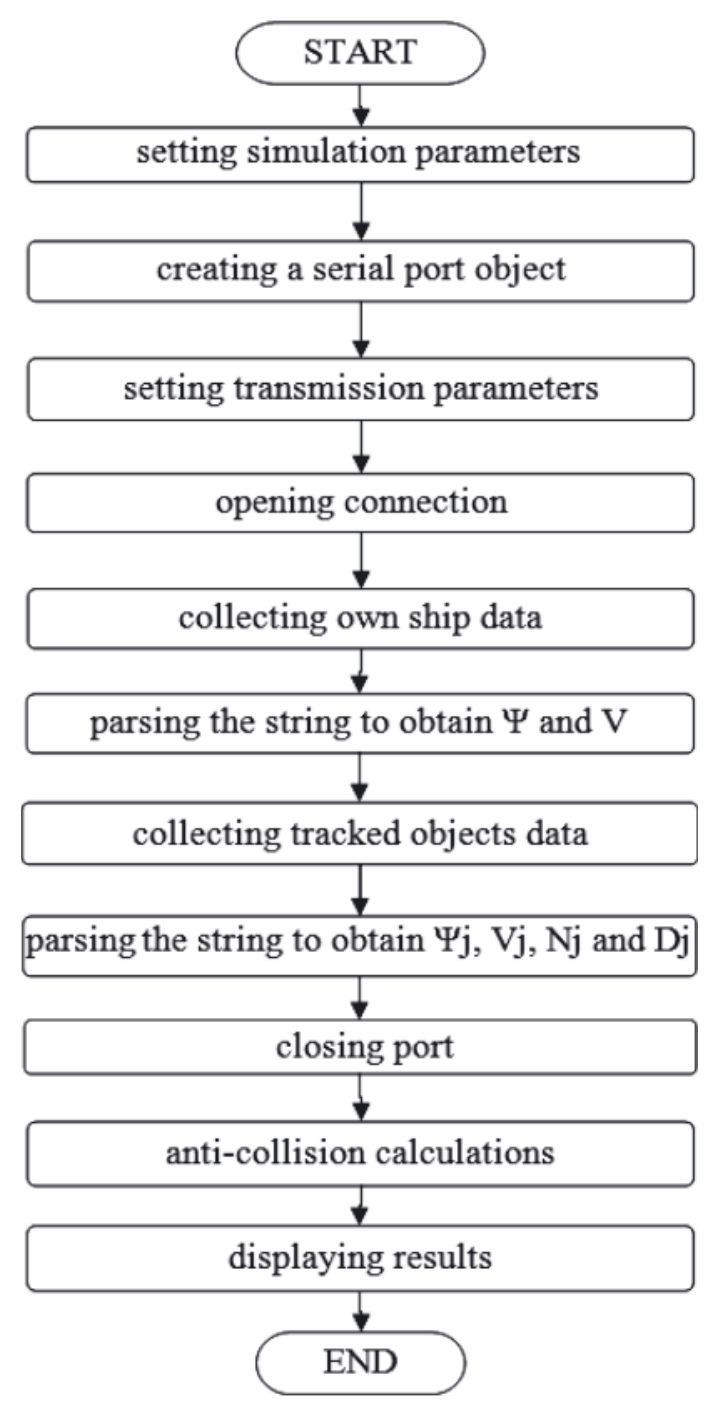

Fig. 5. Diagram of communication algorithm integrated with decision support system. $\boldsymbol{\Psi}$-own ship course, $\boldsymbol{V}$-own ship speed, $\boldsymbol{\Psi} \boldsymbol{j}$-tracked object course, $\boldsymbol{V j}$-tracked object speed, $\boldsymbol{N} \mathbf{j}$-tracked object bearing from own ship, Dj-tracked object distance from own ship

of own ship to the next waypoint determined by global path planner. This local route is determined with the use of dynamic programming algorithm. While for the determination of global path in PSS algorithm Ant Colony Optimization is proposed. Global path planning algorithm takes into account navigational obstacles in the form of land, canals, shallows etc.

Ant Colony Optimization operation principle is based on ant colonies foraging behaviour. It has been developed that ants, while moving between food source and their nest, deposit chemicals on the ground called pheromones. Other ants smell this pheromone trail and choose the path marked by stronger pheromone concentrations. Investigation of this trail-laying and trail-following behaviour of some ant species have shown that this indirect communication called stigmergy forms a method in which ants find the shortest path between food source and their nest.

ACO algorithms belong to the branch of artificial intelligence called swarm intelligence. Swarm intelligence is concerned about design of multi-agent systems. It takes inspiration from the collective behaviour of social insects such as ants, bees, wasps and termites. In analogy to real ants behaviour, ACO is based on indirect communication of a colony of simple agents called artificial ants. The ACO approach to solving optimization problems was first introduced by Dorigo in collaboration with Colorni and Maniezzo in the early 1990's.
The representation of a problem with the use of ACO is as follows. If a minimization problem $(\mathrm{S}, \mathrm{f}, \Omega)$ is considered, $\mathrm{S}$ is the set of candidate solutions, $f$ is the objective function and $\Omega$ is the set of constraints. The objective function $\mathrm{f}$ assigns an objective function cost value $\mathrm{f}(\mathrm{s}, \mathrm{t})$ to each candidate solution $\mathrm{s} \in \mathrm{S}$. The aim is to find a globally optimal solution $\mathrm{s}_{\mathrm{opt}} \in \mathrm{S}$, it means a minimum cost solution that satisfies the constraints $\Omega$. The description of the problem exploited by the ants include a finite set $\mathrm{C}=\left\{\mathrm{c}_{1}, \mathrm{c}_{2}, \ldots, \mathrm{c}_{\mathrm{N}_{\mathrm{c}}}\right\}$ of components. The problem states are defined as a sequence $\mathrm{x}=\left\langle\mathrm{c}_{\mathrm{i}}, \mathrm{c}_{\mathrm{j}}, \ldots, \mathrm{c}_{\mathrm{k}}, \ldots\right\rangle$ over the elements of $\mathrm{C}$. $\mathrm{X}$ is a set of all possible sequences and $|\mathrm{x}|$ is the number of component in the sequence $\mathrm{X}$, denoted as the length of a sequence $\mathrm{x}$. The set of feasible states $\overline{\mathrm{X}}$ with $\subseteq \overline{\mathrm{X}} \subseteq$ $\mathrm{X}$ is defined by the finite set of constraints $\Omega$. A set of feasible solutions is denoted by $\mathrm{S}^{*}$ (with $\mathrm{S}^{*} \subseteq \overline{\mathrm{X}}$ and $\mathrm{S}^{*} \subseteq \mathrm{S}$ ). Each candidate solution $\mathrm{s} \in \mathrm{S}$ have a cost $\mathrm{f}(\mathrm{s}, \mathrm{t})$ associated.

It spite of above-mentioned definition of the problem, it can be considered, whether to implement constraints $\Omega$ in a hard way allowing ants to build only feasible solutions or in a soft way, where ants can also build infeasible solutions, which will be penalized then, in dependence of their degree of infeasibility.

The travelling salesman problem was the first application of ACO algorithm. In this path optimization problem the goal is to find a minimal length closed route connecting $\mathrm{m}$ given cities, on the assumption that each city can be visited only once.

The problem definition can be presented in Euclidean space, where the distance between two cities $\mathrm{i}$ and $\mathrm{j}$ is described as follows:

$$
d_{i j} \sqrt{\left(x_{i}-x_{j}\right)^{2}+\left(y_{i}-y_{j}\right)^{2}}
$$

where:

$\mathrm{x}_{\mathrm{i}}$ and $\mathrm{y}_{\mathrm{i}}-$ the coordinates of city $\mathrm{i}$,

$x_{j}$ and $y_{j}-$ the coordinates of city $j$.

It can also be described as a graph $(\mathrm{N}, \mathrm{E})$, where the nodes $\mathrm{N}$ are defined by the cities and the connections between the cities are presented as the edged $\mathrm{E}$ of the graph.

Given the problem representation as stated above, during every iteration of algorithm, each ant $\mathrm{k}(\mathrm{k}=1, \ldots, \mathrm{m})$ moves on the problem graph from one city to another by applying a probabilistic transition rule, until it completes the tour. The transition rule is expressed by:

$$
p_{i j}^{k}(t)=\frac{\left[\tau_{i j}(t)\right]^{\infty} \cdot\left[\eta_{i j}\right]^{\beta}}{\sum_{l \in N_{i}^{k}}\left[\tau_{i j}(t)\right]^{\infty} \cdot\left[\eta_{i j}\right]^{\beta}} \quad \text { if } j \in N_{1}
$$

where $\tau_{i j}(t)$ is the amount of virtual pheromone trail on the edge connecting city $i$ to city $j$, which reflects the experience acquired by ants during problem solving, $\eta_{i j}=1 / d_{i j}$ is a heuristic information called visibility. Parameters $\alpha$ and $\beta$ determine the relative influence of pheromone trail and heuristic information and $\mathrm{N}_{\mathrm{i}}^{\mathrm{k}}$ is the set of cities which ant $\mathrm{k}$ has not yet visited, when it is in city $i$. When the solution construction at present iteration ends, the pheromone trails are updated. The expression defining this procedure is given by:

$$
\tau_{\mathrm{ij}}(\mathrm{t}+1)=(1-\rho) \cdot \tau_{\mathrm{ij}}(\mathrm{t})+\sum_{\mathrm{k}=1}^{\mathrm{m}} \Delta \tau_{\mathrm{ij}}^{\mathrm{k}}(\mathrm{t})
$$

where $\rho$ is the pheromone trail evaporation rate, which enables the algorithm to "forget" bad decisions previously made by the ants, $\Delta \tau_{\mathrm{ij}}^{\mathrm{k}}(\mathrm{t})$ is the amount of pheromone ant $\mathrm{k}$ deposits on arcs belonging to its tour and is defined as: 


$$
\Delta \tau_{\mathrm{ij}}^{\mathrm{k}}(\mathrm{t})=\left\{\begin{array}{cl}
\frac{1}{\mathrm{~L}^{\mathrm{k}}(\mathrm{t})} & \text { if } \operatorname{arc}(\mathrm{i}, \mathrm{j}) \text { is used by ant } \mathrm{k} \\
0 & \text { othervise }
\end{array}\right.
$$

Ship's path planning problem is represented by a graph $(\mathrm{N}$, $\mathrm{E}$ ), where nodes $\mathrm{N}$ are placed in acceptable waypoints and edges E connecting these nodes, for which passing of a ship is possible without transgressing constraints [26, 27, 28, 29, 30].

\section{CONCLUSIONS}

Designed decision support system enables to automatically determine safe manoeuvre or safe trajectory with the use of information from automatic radar plotting aid. The system provides possibility to implement different methods of determining safe ship trajectory in collision situation other than applied dynamic programming and to verify their performance in real navigational situation and in real electro-navigational system onboard a ship. Further research is conducted to make a system independent from Matlab environment and implemented in $\mathrm{C}$ programming language to constitute a stand-alone application (Fig. 8). Figs 6 and 7 present graphic

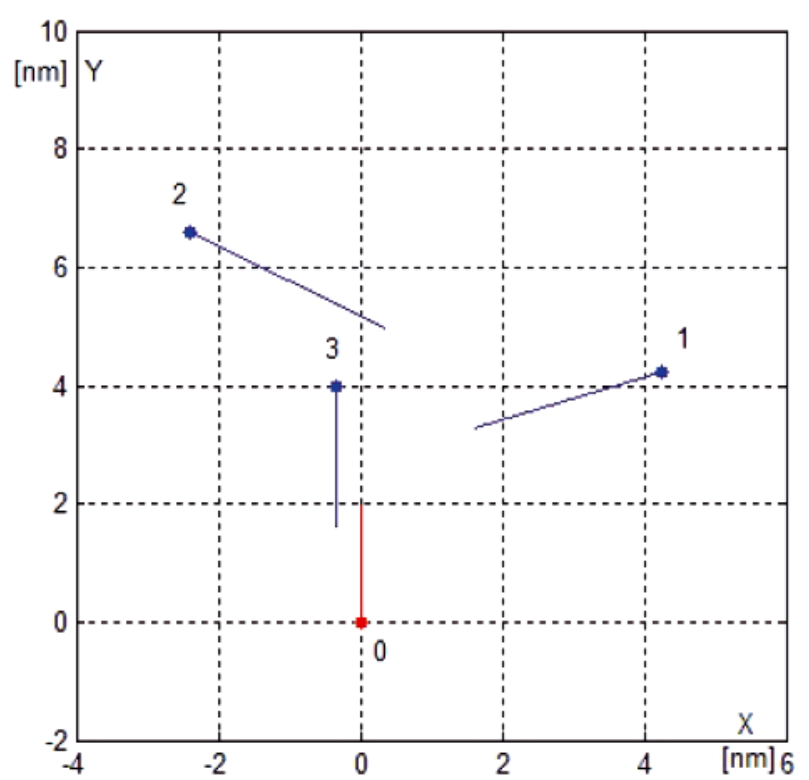

Fig. 6. Navigational situation of 3 encountered objects

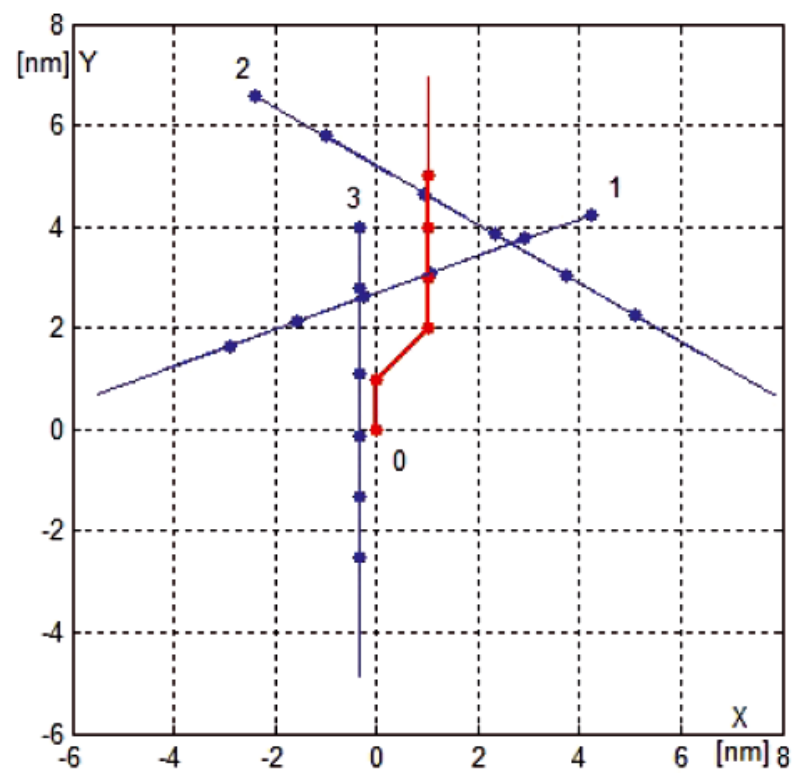

Fig. 7. Own ship's safe trajectory in the situation of 3 encountered objects representation of navigational situation solved by $\mathrm{C}$ language implementation of dynamic programming algorithm. In an expanded version the decision support system could present safe trajectory on ARPA display or Electronic Chart Display and Information System (ECDIS) display with the proposed value of course and/or speed change of own vessel. Further development of the system could lead to full automation of the process of safe ship control. It could be achieved by sending rudder order after confirmation by the deck officer. Joined with the path planning system onboard the ship would enable automatic passage from point $A$ to point $B$, because the system would be capable of automatically solving collision situations at sea.

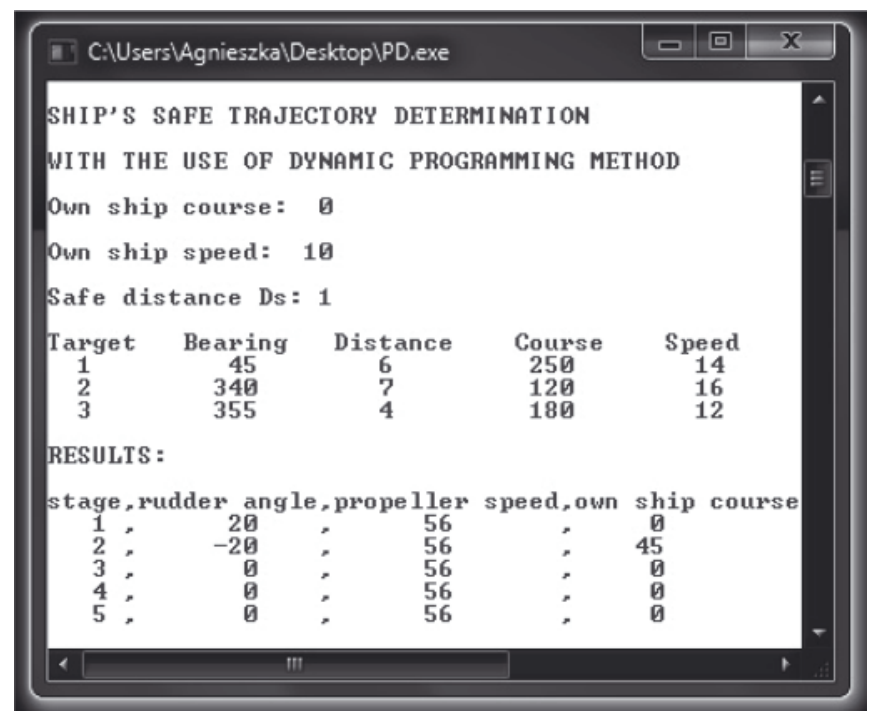

Fig. 8. Results of ship's safe trajectory determination with the use of dynamic programming algorithm implemented in $C$ programming language

\section{BIBLIOGRAPHY}

1. Wołejsza P., Szewczuk T.: Analysis of navigational data availability on the basis of $\mathrm{m} / \mathrm{s}$ Nawigator XXI. Scientific Journals, Maritime University of Szczecin. No. 13(85), 2008, p.115-119.

2. Bole A., Dineley B: Radar and ARPA manual. ButterworthHeinemann Ltd, Oxford, 2000.

3. Rothblum A.M., Wheal D., Withington S., Shappell S.A., Wiegmann D.A., Boehm W., Chaderjian M.: Key to successful incident inquiry. In: Proceedings 2nd international workshop on human factors in offshore operations, HFW2002, Houston, TX, p. $1-6$.

4. Cockcroft A.N., Lameijer J.N.F.: a guide to collision avoidance rules. Elsevier, Amsterdam-Tokyo, 2004.

5. Lisowski J.: Computational intelligence methods in the safe ship control process. Polish Maritime Research. No. 1,Vol. 8, 2001, p. $18-24$.

6. IEC 61162-1 International Standard: Maritime navigation and radio communication equipment and systems - Digital interfaces - Part 1: Single talker and multiple listeners.

7. Documents for Operators and Engineers: Operating Instructions RADARPILOT 1100, Service Manual IEC-Interface. SAM Electronics, 2005.

8. Daniluk A.: RS 232C-practical programming. From Pascal and $C++$ to Delphi and Builder, Helion, Warszawa, 2007 (in Polish).

9. Lisowski J.: Optimal and game ship control algorithms for avoiding collisions at sea. In C.A. Brebbia (Ed), Risk Analysis VI: Simulation and Hazard Mitigation, WIT Press Computational Mechanics Inc., Southampton-Boston, 2008, p. 525-534.

10.Lisowski J.: Sensitivity of Safe Game Ship Control. 16th Mediterranean Conference on Control and Automation Congress Centre, Ajaccio, France, 2008, p.220-225. 
11.Lisowski J.: The Dynamic Game Models of Safe Navigation. TransNav - International Journal of Marine Navigation and Safety of Sea Transportation, Vol.1, No.1, 2007, p. 11-18.

12.Lisowski J.: The dynamic game theory methods applied to ship control with minimum risk of collision. In C.A. Brebbia and V.Popov (Ed), Risk Analysis V: Simulation and Hazard Mitigation, WIT Press Computational Mechanics Inc., Southampton-Boston, 2006, p. 293-302.

13.Lisowski J.: Multi-step matrix game with the risk of ship collision. In C.A. Brebbia (Ed), Risk Analysis IV: Simulation and Hazard Mitigation, WIT Press Computational Mechanics Inc., Southampton-Boston, 2004, p. 669-680.

14.Pietrzykowski Z., Uriasz J..: Knowledge Representation in a Ship's Navigational Decision Support System. TransNav - International Journal of Marine Navigation and Safety of Sea Transportation, Vol.4, No.3, 2010, p. 265-270.

15.Zhuo Y., Hearn G.E.: a ship based intelligent anti-collision decision-making support system utilizing trial manoeuvers. Proceedings of 2008 Chinese control and decision conference, CCDC 2008, Yantai, China, p. 3982-3987.

16.Perera L.P., Carvalho J.P., Guedes Soares C.: Fuzzy logic based decision making system for collision avoidance of ocean navigation under critical collision conditions. Journal of Marine Science and Technology, Vol. 16, No. 1, 2011, p.84-99.

17.Lee S.-M., Kwon K.-Y., Joh J.: a Fuzzy Logic for Autonomous Navigation of Marine Vehicles Satisfying COLREG Guidelines. International Journal of Control, Automation, and Systems, Vol. 2, No. 2, 2004, p.171-181.

18.Hwang C.-N., Joe-Ming Yang J.-M., Chiang C.-Y.: The design of fuzzy collision-avoidance expert system implemented by $H \infty-$ autopilot. Journal of Marine Science and Technology, Vol. 9, No. 1, 2001, p. 25-37.

19.Śmierzchalski R., Michalewicz Z.: Modeling of ship trajectory in collision situations by an evolutionary algorithm. IEEE Transactions on Evolutionary Computation, Vol. 4, No. 3 , 2000, p.227-241.

20.Cheng X.D., Liu Z.Y., Zhang X.T.: Trajectory optimization for ship collision avoidance system using genetic algorithm. Proceedings OCEANS 2006 - Asia Pacific, Singapore, p. 1-5.
21.Lisowski J.: Optimization decision support system for safe ship control. In C.A. Brebbia (Ed), Risk Analysis VII: Simulation and Hazard Mitigation, WIT Press Computational Mechanics Inc., Southampton-Boston, 2010, p. 259-272.

22.Lisowski J.: Multistage ship's optimal control in collision situations using a neural network. II International Conference Safe Navigation Beyond, 2000, p.109-119.

23.Lisowski J., Pachciarek A.: Navigational data transmission in computer navigator's decision support system in collision situation. Telecommunication review, No. 1, 2009, p. 33-35 (in Polish).

24.Pachciarek A.: Project of navigator's decision support system with the use of algorithms determining safe trajectory of a ship. MSc thesis, Gdynia Maritime University, 2008, (in Polish).

25.Tran T., Harris C.J., Wilson P.A.: Maritime Avoidance Navigation, Totally Integrated system (MANTIS). 12th SCSS 1999 - 12th Ship Control Systems Symposium, The Hague, The Netherlands, Royal Dutch Navy.

26.Blum C.: Ant colony optimization: Introduction and recent trends. Physics of life Reviews, No. 2(4), p.353-373, 2005.

27.Dorigo M., Stützle T.: The Ant Colony Optimization Metaheuristic: Algorithms, Applications, and Advances. Handbook of Metaheuristics, 2002.

28.Dorigo M., Di Caro G., Gambardella L.M.: Ant Algorithms for Discrete Optimization.Artificial Life, No. 5(2), p.137-172, 1999.

29.Szłapczyńska J.: Application of evolutionary algorithms and rank-based methods for path planning of a vessel with hybrid propulsion. Doctoral thesis, West Pomeranian University of Technology, Szczecin, 2009 (in Polish).

30.Wiśniewski B.: Ship Ocean Route Programming. Scientific Journals, Maritime University of Szczecin. No. 2(74), 2004, p.395-406.

\section{CONTACT WITH THE AUTHOR}

Agnieszka Lazarowska, M.Sc. Faculty of Marine Electrical Engineering,

Gdynia Maritime University, Morska 81-87

81-225 Gdynia, POLAND

e-mail: aglaz@am.gdynia.pl 